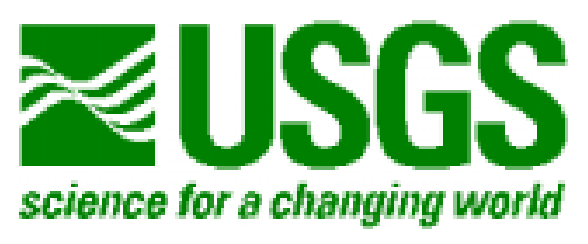

\title{
HYDROGEOCHEMICAL DATA FOR HISTORIC MINING AREAS, HUMBOLDT WATERSHED AND ADJACENT AREAS, NORTHERN NEVADA
}

By

\section{J. Thomas Nash ${ }^{1}$}

Open-File Report 00-459

2000

This report is preliminary and has not been reviewed for conformity with U. S.

Geological Survey editorial standards or with North American Stratigraphic code. Any use of trade, product or firm names is for descriptive purposes only and does not imply endorsement by the U.S. Government.

\section{U. S. Department of the Interior \\ U. S. Geological Survey}

${ }^{1}$ Geologic Division, Box 25046 MS 973, Denver CO 80225; tnash@usgs. gov 


\section{TABLE OF CONTENTS}

Introduction 3

Field Methods $\quad 4$

Water sampling and analysis $\quad 4$

$\begin{array}{ll}\text { Sampling and analysis of mineralized rocks } & 7\end{array}$

$\begin{array}{lr}\text { Data Files } & 9\end{array}$

$\begin{array}{ll}\text { Quality control for water analyses } & 10\end{array}$

$\begin{array}{ll}\text { References cited } & 13\end{array}$

List of figures and tables

$\begin{array}{lr}\text { Figure 1: Diagram of analytical error } & 12\end{array}$

Table 1: Elements determined in water and leachate solutions by ICP-MS 7 


\section{INTRODUCTION}

This report contains the analytical results for samples collected at 641 sites in the Humboldt River watershed and adjacent mining areas. Included are results for 273 samples of surface waters, 225 samples of mined rocks, mill tailings, and altered rocks, and passive leach analyses of 162 samples of those mineralized materials. These geochemical analyses are part of studies designed to characterize the geochemical signature of historic mines and to determine their actual or potential contamination of surface or ground waters. Although there are several thousand small prospects, numerous small mines, and about 50 large mines in the area of the Humboldt River watershed in northern Nevada, the approach in this investigation was to identify the larger examples of abandoned historic mines for observation and sampling. In most districts, the selected sites are the worst cases of likely contamination. Forty districts with significant historic mining activity were examined and sampled, but no active mines were investigated. This study is similar in methods, and provides similar results to the investigation of Price and others (1995).

Field observations suggest that visible indicators of acidic mine drainage (such as red iron precipitates) are rare, and field measurements of $\mathrm{pH}$ and chemical analyses of several kinds of materials (dump rocks, tailings, surface waters) indicate that only a few sites release acid or significant concentrations of metals. The most consistent observation at and near the studied mining areas is neutral to weakly alkaline pH's (6.5 to 8.4) and water compositions reflecting significant amounts of carbonate derived from rocks, alluvium, and caliche-bearing soils. The alkalinity of surface waters generally is sufficient to naturally mitigate local sources of acidic waters.

The emphasis of these geochemical studies was on materials and processes that are actively, or have the potential to contribute acid or metals to surface waters. Water samples were collected wherever possible from springs, mine adits, streams, mine pits or puddles, and where there was no accessible water (ground water was not sampled) solid materials were collected and tested in the laboratory, using a passive leach test, for their potential to release acid and metals. Although the results for many metals of concern are reported to levels below 1 part per billion, the focus of this study is on the high concentrations that span four to six orders of magnitude for toxic metals such as $\mathrm{Cu}$ and $\mathrm{Zn}$. This investigation is concerned with geochemical processes that create those very high metal concentrations, and the geologic processes that attenuate $\mathrm{pH}$ and high metal concentrations. The analytical methods used are appropriate for determination of many metals of potential concern and expected to have a wide range in concentration, and the ICP-MS method in particular is good for trace metals in water such as $\mathrm{As}, \mathrm{Cu}, \mathrm{Pb}$, and Zn. (Crock and others, 1999). A secondary goal of these hydrogeochemical studies is screening of mining sites of interest to Federal land managers. If water compositions reported here suggest a problem source of contamination, follow-up work should be done using trace-metal sampling protocols and more precise analytical methods appropriate for water quality definition. 
Acknowledgements. This study has benefited in many ways from helpful suggestions from staff of the BLM and USFS in Nevada. My colleagues in the USGS have offered helpful advice, comments on manuscripts, and chemical analyses; I thank in particular Paul Briggs, Jim Crock, David Fey, John Gray, Phil Hageman, Al Meier, Bill Miller, Lisa Stillings, Doug Yager, and Alan Wallace.

\section{FIELD METHODS}

Field studies were conducted during eight visits from1995 to 1999; studies were made chiefly in May and June when surface waters were more commonly available for sampling. Sites visited and sampled were determined by published information, U.S. Geological Survey records in the Mineral Resources Data System (MRDS), information on U.S. Geological Survey 1:24,000 scale topographic maps, and by accessibility. Sample localities were recorded on the topographic maps and measured with a conventional GPS (global positioning system) instrument having an accuracy of about \pm 100 to 150 feet (horizontal) based on tests at known sites.

A six to eight digit identifier was assigned to each site or sample; an example is NHW555. The first three or four digits are letters. The first two characters, NH, designate the sampler (Nash) and study area (Humboldt). The third or fourth character designates the sample media or site type, most commonly $\mathrm{D}$, mine waste dump rocks; $\mathrm{R}$, altered (unmined) rocks; W, water (of several types); L, leachate derived from a lab test. Other types are explained in the data tables. The date of collection can be discerned from the sample number sequence, which runs as follows:

$\begin{array}{ll}\text { NH100-NH113: } & \text { September, 1995 (dry) } \\ \text { NH150-NH163: } & \text { June, 1996 (some water) } \\ \text { NH200-NH269: } & \text { July, 1996 (dry) } \\ \text { NH300-NH343: } & \text { September, 1996 (dry) } \\ \text { NH400-NH534: } & \text { May, 1997 (snow and rain) } \\ \text { NH550-NH694: } & \text { June, 1997 (rain, wet) } \\ \text { NH700-NH858: } & \text { May, 1998 (snow and rain) } \\ \text { NN900-NN999, NN100-NN144: } & \text { June, 1999 (snow and rain) } \\ \text { NN0200-NN0330 } & \text { June, 2000 (hot, dry) }\end{array}$

Numbers outside of the sequences above were used for sample duplicates. The brief remarks on weather given above are an indication of favorability for collecting water samples. The late spring seasons of 1997, 1998, and 1999, were unusually wet.

\section{Water sampling and analysis}

The focus of these geochemical studies was the composition of surface waters. Analyses of surface waters provide a quantitative measure of what contaminants are mobile in the vicinity of mines and available to wildlife and humans. Water samples were collected from mines and streams when the water was deemed to be representative of a geologic or mine setting and would yield information on the mobility of metals in that 
environment. The sampling methods have been used by the author since 1994 for reconnaissance characterization of geologic units, rock alteration, mine drainage, and reactions with tailings or dump materials (Nash and others, 1996); these methods are similar to but simplified from those described by Ficklin and Mosier (1999). First, flow rate and water characteristics (color, suspended material, bed colors or mineralogy) are recorded, and $\mathrm{pH}$ and conductivity are measured using portable instruments.. The pocketsized conductivity meter (Corning CD-55), with an upper limit of 2,000 $\mu \mathrm{S} / \mathrm{cm}$, responded consistently and showed no drift after calibration. The $\mathrm{pH}$ meter (Orion 250), with built in temperature electrode, required frequent calibration during the day, and at most sites the calibration was checked on a standard solution after the field measurement. The field standards were buffered solutions of $\mathrm{pH} 4.0,7.0$, and 10.0 I consider the measurements of $\mathrm{pH}$ to carry an uncertainty of about \pm 0.05 standard units, even though the meter reports to 0.01 units, because of instrument drift that possibly is larger than normal in the analysis of widely divergent compositions. A representative water sample for analysis was collected with a disposable $60 \mathrm{ml}$ syringe, then pushed through a disposable 0.45 micron cellulose filter. The syringe and the 60 or $120 \mathrm{ml}$ polyethylene bottle were rinsed twice in the sampled water prior to collection. The filtered sample was acidified to a $\mathrm{pH}$ of about 2 at the site with 5 drops of ultrapure $1: 1 \mathrm{HNO}_{3}$ per $60 \mathrm{ml}$. At appropriate localities (with $\mathrm{pH}>4$ ) an unfiltered sample was collected for determination of alkalinity. Lab and field blank tests using deionized water, indicated that contamination introduced by the sampling procedure and equipment is in the low parts per billion level (1-10 ppb), which I consider adequate in the search for metal concentrations that are orders of magnitude greater than the sampling error. Each group of analyzed water samples included standard solutions and replicate samples (blind to the analyst); quality control is described in Appendix I and in other reports (Lamothe and others, 1999; Fey and others, 2000).

Water samples were analyzed by several methods for various constituents using methods described by Crock and others (1999). Concentrations of 40 to 60 elements (cations) were determined by inductively coupled plasma-mass spectrometry (ICP-MS) by a commercial laboratory (1996 to 1998 samples) and by the USGS (1999 samples). The elements and the lower limit of determinations are listed in table 1. Element concentrations were also determined by inductively coupled plasma-atomic emission spectrometry (ICP-AES) for 24 cations, many of which are the same as detected by ICPMS but the ICP-AES is considered better suited for higher concentration levels of major elements. Some of the ICP-AES analyses were made by the USGS and others were made at the University of Montana. In this report the analytical results are kept separate for the several methods and laboratories because analytical errors and limits of determination differ among the methods. For some purposes a user may wish to combine results in ways that are appropriate to the application, for instance use the results for major elements $(\mathrm{Ca}, \mathrm{Fe}, \mathrm{Mg}$, Na, etc.) from ICP-AES in place of those by ICP-MS, and the results for trace metals ( $\mathrm{As}, \mathrm{Cd}, \mathrm{Cu}, \mathrm{Pb}, \mathrm{Zn}$, etc) from ICP-MS if values to very low concentration levels are needed. Note that although most results are reported in parts per billion ( $\mathrm{ppb}$ or micrograms/liter), some results are in parts per million ( $\mathrm{ppm}$ or milligrams/liter). 
Sampling in 1998 and 1999 included additional aliquots for supplemental analyses of anions and alkalinity. These samples were filtered but not acidified in the field (added acid would interfere with or negate these analyses). The anions $(\mathrm{Cl}, \mathrm{F}, \mathrm{NO} 3$, and SO4) were determined by ion chromatography (IC) and reported in ppm; some of the IC anion analyses were made by the USGS and others were made at the University of Montana. Alkalinity is determined by titration (Gran technique) and expressed in equivalent $\mathrm{CaCO} 3(\mathrm{mg} / \mathrm{l})$.

Mercury in water requires special preservation methods in the field to ensure that the $\mathrm{Hg}$ is available for analysis; in normal methods $\mathrm{Hg}$ adsorbs on plastic bottles and that fraction is not available for analysis, as by ICP-MS. A limited suite of samples were collected in 1998 using nitric acid-sodium dichromate and special glass bottles (Crock, 1996). Analysis for Hg in water samples was by CV-AAS (cold vaporatomic absorption spectrometry) and AFS (atomic fluorescence spectrometry) (Crock and others, 1999). The Hg samples were either filtered or unfiltered, depending upon the question being asked (unfiltered samples show total $\mathrm{Hg}$, including that adsorbed on fine particles). More complete information on $\mathrm{Hg}$, analytical methods, and occurrence in the study area can be found elsewhere (Gray and others, 1999). 
Table 1: Elements determined in water and leachate solutions by ICP-MS [Elements are listed by atomic weight; lower limit is in parts per billion (micrograms/liter; the limits shown are generalized and somewhat higher than stated by the commercial lab; limits in USGS analyses are similar].

$\begin{array}{llll}\mathrm{Li} & 0.1 & \mathrm{Nb} & 0.01 \\ \mathrm{Be} & 0.5 & \mathrm{Mo} & 0.04 \\ \mathrm{Na} & 0.8 & \mathrm{Ag} & 0.01 \\ \mathrm{Mg} & 0.5 & \mathrm{Cd} & 0.01 \\ \mathrm{Al} & 0.4 & \mathrm{Sn} & 0.01 \\ \mathrm{Si} & 1 & \mathrm{Sb} & 0.04 \\ \mathrm{~K} & 1 & \mathrm{Te} & 0.2 \\ \mathrm{Ca} & 1 & \mathrm{Cs} & 0.01 \\ \mathrm{Sc} & 0.1 & \mathrm{Ba} & 0.01 \\ \mathrm{Ti} & 0.04 & \mathrm{La} & 0.01 \\ \mathrm{~V} & 0.04 & \mathrm{Ce} & 0.01 \\ \mathrm{Cr} & 0.04 & \mathrm{Eu} & 0.01 \\ \mathrm{Mn} & 0.04 & \mathrm{Yb} & 0.01 \\ \mathrm{Fe} & 0.3 & \mathrm{Ta} & 0.01 \\ \mathrm{Co} & 0.01 & \mathrm{~W} & 0.01 \\ \mathrm{Ni} & 0.01 & \mathrm{Re} & 0.01 \\ \mathrm{Cu} & 0.01 & \mathrm{Os} & 0.01 \\ \mathrm{Zn} & 0.01 & \mathrm{Pt} & 0.01 \\ \mathrm{Ga} & 0.01 & \mathrm{Au} & 0.01 \\ \mathrm{As} & 0.04 & \mathrm{Tl} & 0.01 \\ \mathrm{Se} & 0.04 & \mathrm{~Pb} & 0.02 \\ \mathrm{Br} & 1 & \mathrm{Bi} & 0.01 \\ \mathrm{Rb} & 0.01 & \mathrm{Th} & 0.01 \\ \mathrm{Sr} & 0.01 & \mathrm{U} & 0.01 \\ \mathrm{Y} & 0.01 & & \\ & & & \end{array}$

\section{Sampling and analysis of mineralized rocks}

Rock chemistry. Rock samples were collected from mine dumps, outcrops, and mill tailings impoundments. In most cases the intent was to collect a representative sample, but for some sites a select sample was collected to determine a special property. The most commonly employed sampling method for dumps and tailings involved the collection of numerous small portions at 20 to 30 sub-sites, and sieving the materials through a $2 \mathrm{~mm}$ stainless steel sieve to derive a composite sample weighing about 2 to 4 pounds; this is the standard protocol developed for USGS-AML investigations (Nash, 1999).

Rock samples were prepared for analysis under the direction of Paul Lechler, Nevada Bureau of Mines and Geology, Reno, and analyzed by two commercial laboratories. In one method the rocks are dissolved in a mixture of four acids, then the 
concentrations of 35 major and trace elements are determined using inductively coupled plasma (ICP); this is considered a total analysis as the strong acids dissolve all but the most refractory minerals such as zircon. This method is essentially that of Briggs (1990), although slight differences may exist between laboratories. Rock samples were also analyzed by a method that employs weaker acids to dissolve most minerals, then employs an organic reagent to collect 15 metals of interest (Ag, $\mathrm{As}, \mathrm{Au}, \mathrm{Bi}, \mathrm{Cd}, \mathrm{Co}, \mathrm{Cu}, \mathrm{Hg}, \mathrm{Mo}$, $\mathrm{Pb}, \mathrm{Sb}, \mathrm{Se}, \mathrm{Te}, \mathrm{Tl}$, and $\mathrm{Zn}$ ); analysis is by ICP; results are very similar to those of Motooka (1990) but include 5 additional elements. This second analytical method has lower levels of determination and works well for some elements, such as $\mathrm{Hg}, \mathrm{Sb}, \mathrm{Se}, \mathrm{Te}$, and $\mathrm{Tl}$, that are not effectively determined by the total digestion method. Total sulfur, determined by combustion, was done on some samples but discontinued because the method does not discriminate among forms of sulfur (such as sulfide and sulfate), thus does not provide as much information for topics such as acid generating potential as desired. Quality assurance monitoring by Lechler shows that the precision and accuracy (deviation of the reported values from correct ones) is less than 5 percent for most elements. Analytical results of chemical analyses of solid materials are in a spreadsheet file NHWG98.xls that is included with this report.

Leachate chemistry. The chemical analyses just described are not always appropriate for environmental characterization because they describe total metal rather than mobile (soluble) metal concentrations. To determine the mobility of metals, as well as the tendency of a material to generate acid, a passive leach test (Nash, 1999; Fey and others, 2000) was utilized. Solid materials from dumps, mill tailings, and outcrops have been processed in the lab by a leach method that provides a measure of reactions in nature, such as during weathering or storm events. Quite simply, 100 g. of rock sample, sieved to $<2 \mathrm{~mm}$, is placed in a beaker with $2,000 \mathrm{ml}$ of deionized water, stirred slightly, and an initial $\mathrm{pH}$ measured. After about 20 hours, the upper part of the solution is stirred gently to mix the leachate solution. At 24 hours the $\mathrm{pH}$ and conductivity of the leachate is measured, and a $60 \mathrm{ml}$. aliquot is taken with a syringe and filtered through a 0.45 micron filter. The sample is acidified with 5 drops of ultrapure $1: 1 \mathrm{HNO}_{3}$. The leachate is analyzed by the same ICP-MS method used for water samples. Anions are not determined by ICP-MS and no work has been done on them in this investigation because the dominant anion in acidic solutions is expected to be sulfate. The analytical results resemble those for surface waters degraded by mine waste. However, unlike the water analyses that show the results of real water-rock interactions, the leachate results show the potential to generate those compositions-actual behavior is more complex and involves factors such as permeability, kinetics, and climate, slope and aspect.

For most rock samples no sample preparation was done for these tests. The majority of dump samples were sieved to pass $2 \mathrm{~mm}$ while in the field. Mill tailings are by their nature ground to fine sand size and were not sieved. Unmined altered rock samples were crushed but not sieved. In a few instances, efflorescent crusts on dump or tailing materials were hand picked in the field or lab to provide material for leaching that is more than 50 percent crust. The samples were dry and friable when placed in the reaction vessel. 


\section{DATA FILES}

Included in this report are 12 files in spreadsheet format (xls as from Microsoft Excel) containing descriptive information on sites that were sampled and analytical results. The analytical results are mostly as reported by the chemists, except that some files have been simplified by deleting elements that are not obviously of high interest (such as ICP-MS results for more than ten rare earth elements) or for which analytical results are deemed unreliable or inappropriate (such as Hg by ICP-MS or Ag by one ICPMS lab). The files include:

1). HSITD.xls: Locations and brief descriptions of 644 sites that were sampled for geochemical analysis in this study. The numerical portion of the site ID is unique (a few were used twice, in error, and those have an A or B and different locations). The site ID is similar to the sample ID used in data files, except that the letter for sample type (such as $\mathrm{W}$ for water, $\mathrm{D}$ for dump) is not included.

2). HGX67C.xls: Analytical results for 225 samples of mine dump rocks, mill tailings, and altered rocks; ICP-AES analyses by commercial laboratories.

3). HW678MS.xls: Analytical results for 149 water samples collected in 1996, 1997, and 1998; ICP-MS analysis by commercial laboratory.

4). HW90MS.xls: Analytical results for cations in 128 water samples collected in 1999 and 2000; ICP-MS analysis by USGS.

5). HW90AES.xls: Analytical results for cations in 128 water samples collected in 1999 and 2000; ICP-AES analysis by USGS

6). HW90ANI.xls: Analytical results for anions and alkalinity in 119 water samples collected in 1999 and 2000; anion and alkalinity analysis by USGS

7). HW98HG: Analytical results for mercury in 18 water samples collected in 1998; analysis by USGS

8). HWMAES.xls: Analytical results for cations in 175 water samples collected from 1996 to 1999; ICP-AES analysis by Murdock Environmental Laboratory at University of Montana.

9). HWMANI.xls: Analytical results for anions in 31 water samples collected from 1996 to 1999; IC analysis by Murdock Environmental Laboratory at University of Montana.

10). HL789MS.xls: Analytical results for 163 leachate solutions from leach tests of mineralized rock samples collected in 1997 and 1998; ICP-MS analysis by commercial laboratory and USGS. 
11). HW98ALK.xls: Alkalinity determinations on 37 water samples collected in 1998; analysis by USGS.

12). HWQC.xls: Analytical results for standards, replicates, and blanks, Humboldt study 1996 to 1999; analysis by ICP-MS by commercial lab and by USGS.

\section{QUALITY CONTROL FOR WATER ANALYSES}

Standards and replicate samples were routinely submitted with field samples through the course of these studies. Approximately 5 percent of the analyzed samples were standards and replicates. A detailed accounting of quality control is beyond the scope of this report. Readers desiring such information should consult Lamothe and others (1999) for the performance of the USGS ICP-MS system. The commercial lab used for the 1996-1998 analyses reported here is similar but is not run in a research mode. The reader can inspect results in file HWQC to judge how precise and accurate the ICP-MS analyses are. The performance differs for various elements, as mentioned below. A contributing factor to analytical error can be the carryover effects when an analyte of low concentration is sequenced after one with high concentrations; the very large range in composition of the Nevada samples and the fact that the 1996-98 samples were not sequenced for analysis by increasing conductivity or likely metal concentrations probably introduced errors to those ICP-MS results. The following trends are evident:

1. Results are reported for four to six orders of magnitude for most elements of interest in these natural waters and leachates, from less than $0.1 \mathrm{ppb}$ (part per billion or microgram per liter) to 100,000 or more than $1,000,000 \mathrm{ppb}$ in some unusual waters. This is a difficult challenge for any method or chemist. These samples often required dilution by amounts of 1:10 to 1:100 to keep the analyte within the calibration range.

2. Precision and accuracy are complex issues and are not the same for all elements and all concentration levels. I assume that analytical error is greater at the very high concentration levels of some of my unusual mine or experimental waters because there are no standards at this level, but documentation of that error is difficult and is incomplete at this date. Replicate samples suggest that precision at very high concentration levels is not much worse than at normal concentrations. Because reliable standards do not exist for waters with very high "trace" metal concentrations $(>10,000$ $\mathrm{ppb}$ ), it is not possible to evaluate accuracy at high levels the way it is done at more normal levels. For reasons that I can not explain, the precision and accuracy for "major" elements (Al, $\mathrm{Ca}, \mathrm{Mg}$, etc) by this method are much lower than for trace metals. The user of these results should consider them semi-quantitative with errors of about 50 percent in some cases (but less in others). Another method, ICP-AES, provides more reliable results for major elements (Crock and others, 1999).

3. Based on standards and replicate samples, the precision for trace metals (such as As, $\mathrm{Cd}, \mathrm{Co}, \mathrm{Cr}, \mathrm{Cu}, \mathrm{Mn}, \mathrm{Mo}, \mathrm{Ni}, \mathrm{Pb}, \mathrm{Sb}, \mathrm{Se}, \mathrm{V}$, and $\mathrm{Zn}$ ) appears to be about 10 percent (1 standard deviation) for normal water concentrations, and possibly 20 percent at very high 
concentrations. The accuracy of determinations on these trace metals seems to be about 10 percent for normal concentrations. The precision and accuracy for Fe, which generally is not a trace metal in these waters, is not as good as for most metals, and possibly is about 20 percent.

4. Some trace metals pose special problems. Mercury is analyzed, but the $\mathrm{Hg}$ is not stable unless preserved by special methods (Crock, 1996), thus for my samples the Hg originally present was not present in the analyte (the analysis is valid, but the sample is not). Silver, a potentially toxic trace metal, should be high in many of my samples, but analytical results for 1996-97 samples are very low and are not considered reliable. Results for Se, Te, and Tl appear to be reasonable but no standards contained these elements; precision is about the same as for other trace elements

5. These ICP-MS results are deemed satisfactory for the objectives of this stud, the classification or ranking of water compositions. This sampling and analysis protocol has been used for five years in Arizona, Nevada, and Colorado AML studies and appears to be reproducible from day to day, year to year, at a total error of about 20 percent for most trace elements. Replicate analyses show that the composition of these acidified water samples change by less than a few per cent after a year of storage at room temperature (D. Fey, USGS, oral communication, 1999). Many replicate samples have an error of about 10 percent, and a few have a higher error.

These error numbers may be better understood by examination of figure 1 . The error bars show that an analysis for a metal with a concentration of about $10,000 \mathrm{ppb}$ is reliably different from one having $1,000 \mathrm{ppb}$ or $100 \mathrm{ppb}$. Figure 1 shows the magnitude of 5, 10, 20, and 30 percent error bars over a wide range of hypothetical metal compositions. Many of the trace metal determinations (eg. $\mathrm{Cu}, \mathrm{Pb}, \mathrm{Zn}$ ) have error bars like those shown for 10 percent, a few $(\mathrm{Cd})$ may be closer to the 5 percent example, and some (eg. Fe) are like the 20 percent example. This plot shows that even with high analytical error ( 20 or 30 percent) the reported values for about $10,000 \mathrm{ppb}$ do not overlap those of a sample with 1,000 or 100,000. The ICP-MS results are appropriate for comparison of water compositions spanning 4 to 6 orders of magnitude ( 1 to 1,000,000 $\mathrm{ppb})$. 


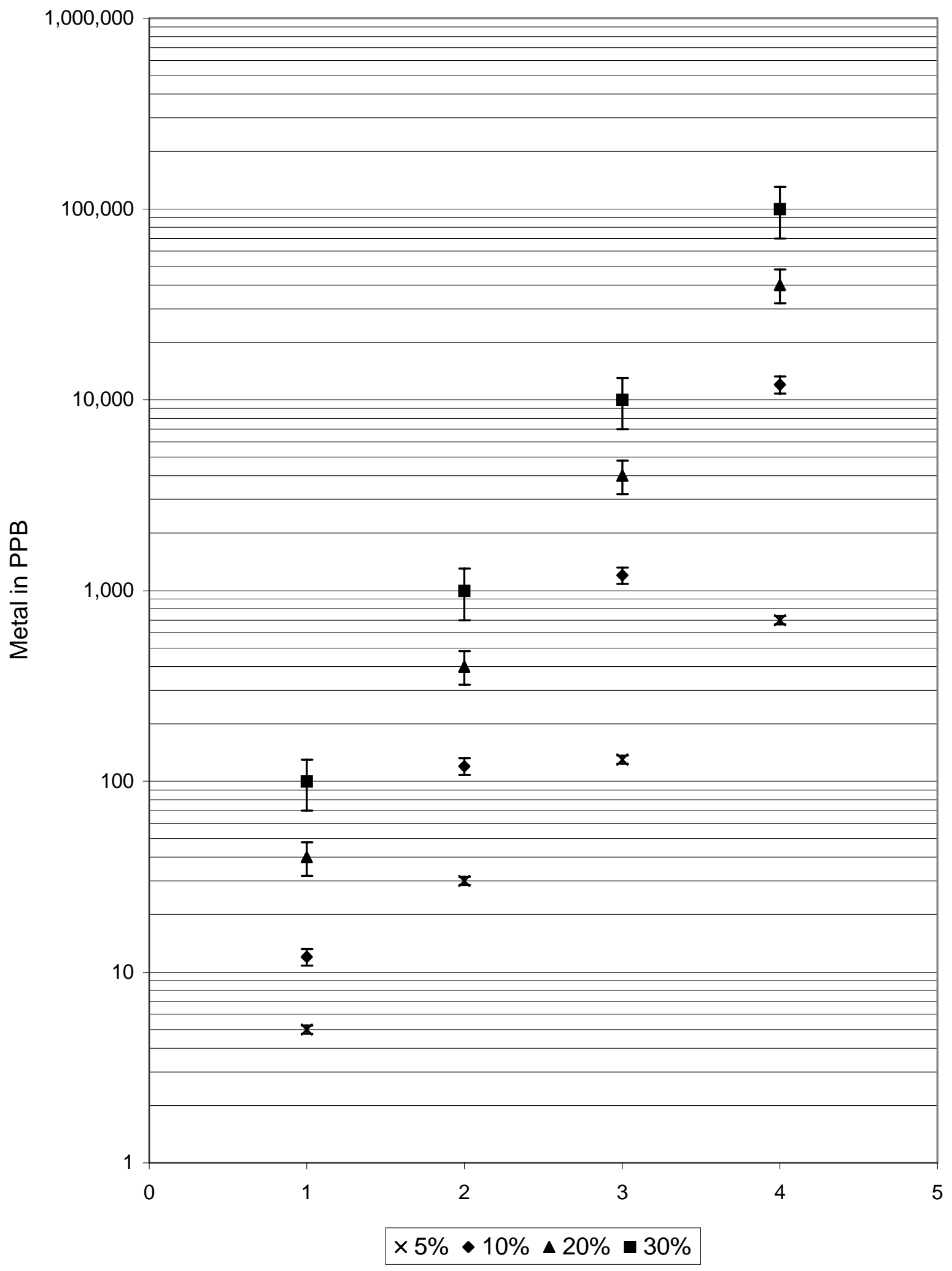

Figure 1: Diagram of analytical error for hypothetical metal concentrations spanning six orders of magnitude. 


\section{REFERENCES CITED}

Briggs, P.H., 1990, Elemental analysis of geologic materials by inductively coupled plasma-atomic emission spectrometry, in Arbogast, B.F., Quality Assurance Manual for the Branch of Geochemistry: U.S. Geological Survey Open-File Report 90-668, p. 83-91.

Crock, J.G., 1996, Mercury, in Methods of Soil Analysis, Part 3, Chemical Methods: Soil Science Society of America, Book Series 5, p. 769-791.

Crock, J.G., Arbogast, B.F., and Lamothe, P.J., 1999, Laboratory methods for the analysis of environmental samples, in Plumlee, G.S., and Logsden, M.J., eds., The Environmental Geochemistry of Mineral Deposits, Part A.: Society of Economic Geologists, Reviews in Economic Geology, Vol. 6, p. 265-287.

Fey, D.L., Desborough, G.A., , and Church, S.E., 2000, Comparison of two leach procedures applied to metal-mining related wastes in Colorado and Montana and a relative ranking method for mine wastes, Proceedings Fifth International Conference on Acid Mine Drainage: Denver, Society for Mining, Metallurgical and Exploration, p. 1477-1488.

Ficklin, W.H., and Mosier, E.L., 1999, Field methods for sampling and analysis of environmental samples for unstable and selected stable constituents, in Plumlee, G.S., and Logsden, M.J., eds., The Environmental Geochemistry of Mineral Deposits, Part A.: Society of Economic Geologists, Reviews in Economic Geology, Vol. 6, p. 249-264.

Gray, J. E., Adams, M.G., Crock, J.G., and Theodorakos, P.M., 1999, Geochemical data for environmental studies of mercury mines in Nevada: USGS Open-File Report 99-576 (CD-ROM).

Lamothe, P.J., Meier, A.L., and Wilson, Stephen, 1999, The determination of forty four elements in aqueous samples by inductively coupled plasma-mass spectrometry: USGS Open-File Report 99-151, 14 p.

Motooka, Jerry, 1990, Organometallic halide extraction applied to the analysis of geologic materials for 10 elements by inductively coupled plasma-atomic emission spectrometry, in Arbogast, B.F., Quality Assurance Manual for the Branch of Geochemistry: U.S. Geological Survey Open-File Report 90-668, p. 92-96.

Nash, J.T., Miller, W.J., McHugh, J.B., and Meier, A.L., 1996, Geochemical characterization of mining districts and related contamination in the Prescott National Forest area, Yavapai County, Arizona: a preliminary assessment of environmental effects: U.S. Geological Survey Open-File Report 96-687, 80 p.

Nash, J.T., 1999, Geochemical investigations and interim recommendations for priority abandoned mine sites, BLM lands, upper Animas River watershed, San Juan County, Colorado: U.S. Geological Survey Open-File Report 99-323, 45 p.

Price, J.G., Shevenell, Lisa, Henry, C.D., Rigby, J.G., Christensen, L.G., Lechler, P.J., Desilets, M.O., Fields, Russ, Driesner, Doug, Durbin, Bill, and Lombardo, Walt, 1995, Water quality at inactive and abandoned mines in Nevada: Nevada Bureau of Mines and Geology, Open-file Report 95-4, 72 p. 